\title{
Adsorption-desorption behavior of thiram: effect of soil type, temperature and $\mathrm{pH}$
}

Zainol Maznah ${ }^{1 *}$, Muhamad Halimah ${ }^{1}$, and Sahid Ismail ${ }^{2}$

\section{ABSTRACT}

The present study was conducted in order to investigate the adsorption and desorption behavior of tetramethylthiuram disulfide (thiram) using the batch equilibration technique in two soil namely: Ultisols and Inceptisols. The adsorptiondesorption isotherms were expressed by the Freundlich equation. The adsorption isotherms of thiram was classified as L-type under Gile's classification. The Freundlich's adsorption coefficient $\left(\mathrm{K}_{d}\right)$ value for thiram in the Ultisols and Inceptisols soil were 3.78 and $2.10 \mathrm{~mL} \mathrm{~g}^{-1}$, respectively. Results indicated that soil organic matter was the main factor affecting thiram behavior in the studied soils. The calculated total percentage desorption values from the Ultisols and Inceptisols soil after the fourth desorption process were $39.2 \%$ and $51.6 \%$, respectively. The negative Gibb's free energy change $\left(\Delta \mathrm{G}^{\circ}\right)$ values obtained suggest that thiram adsorption is an exothermic process. The effects of temperature $\left(25,30\right.$, and $\left.35^{\circ} \mathrm{C}\right)$ and soil $\mathrm{pH}(3,7,10)$ were also studied on adsorption of thiram in the test soils. Results showed that adsorption of thiram was not affected by temperature but clearly affected by soil $\mathrm{pH}$.

Key words: Thiram, adsorption, desorption, soil, temperature, $\mathrm{pH}$.

\section{INTRODUCTION}

Intensive application of pesticides in the agricultural sector and for domestic purposes has resulted in increased usage over the years. Pesticides are used to control pests, diseases and weeds in agricultural and urban areas, but their persistence in the environment has resulted in human poisoning, health risk problem and environmental pollution due to their ability to permeate the soil surface, groundwater systems and water surface bodies (Rama Krishna and Philip, 2008). When pesticides are introduced into the environment through spraying on crops, droplets of pesticides fall on the soil, plant and water. Hence, it is important to understand the mechanism of interactions that occur between pesticide compounds and their behavior in the environment.

The behavior of pesticides in soils and aquatic sediments strongly depend on adsorption-desorption phenomena (Kumar et al., 2015). The adsorption of pesticides to the soil is the key process that affects their ecotoxicological impact, environmental mobility and their rate of degradation. The desorption process of the pesticide determines rate of release and potential mobility of the pesticide in soil (Rama Krishna and Philip, 2008; Liu et al., 2010). Pesticide sorption or binding in the soil has been characterized by determining partitioning of the pesticide between soil and solution, resulting in pesticide sorption coefficients $(\mathrm{Kd})$ (Wauchope et al., 2002; Berglof et al., 2003). Adsorption-desorption isotherms are usually described by linear models and/or Freundlich models. It has been shown that sorption-desorption capacity of pesticides in soils depend on the type of soil, temperature, $\mathrm{pH}$ and properties of pesticide itself (Ismail and Maznah, 2006; Cao et al., 2008; Li et al., 2011).

The fungicide tetramethylthiuram disulphide (thiram) is a nonsystemic dimethyl dithiocarbamate fungicide with a preventive activity and a broad spectrum of action, well-tolerated by crops and seeds (Thomas, 2001; Zahoor, 2010). Thiram is widely used for the control of soil fungi that cause root rot diseases of plants, protection of seed and fruit as well as an animal repellent to protect fruit and ornamental plants from rabbits, rodents and deer (Zahoor, 2010; Sharma et al., 2011). Halimah et al. (2010) reported that the common fungicides used in oil palm nurseries were thiram, mancozeb, benomyl, carbendazim, and dithane. Thiram and propineb were proposed for the control of Curvularia seedling blight (or nursery spot) which requires prophylactic fungicidal treatment using contact chemicals (Mathews et al., 2010).

Certain environmental behavioral patterns of thiram has been reported, these include degradation (Gupta et al., 2011; Sherif et al.,
Received: 8 March 2016.

Accepted: 30 May 2016.

doi:10.4067/S0718-58392016000300016 
2011), fate study (Sharma et al., 2011; Maznah et al., 2012), and photolysis (Filipe et al., 2013). Several research studies have been conducted to investigate the adsorption-desorption phenomena of thiram in soil, and results showed that a strong interaction existed between thiram and commercial humid acids, suggesting the relevance of organic matter on thiram sorption in soils (Filipe et al., 2009). Filipe et al. (2010) also confirmed the effect of soil amendments on thiram sorption and desorption onto a Luvisol soil. An earlier study by Valverde-Garcia et al. (1988) also reported a positive correlation between adsorption of thiram onto Almería soil with the organic matter and clay content of the soil.

Currently, adsorption-desorption phenomena of the pesticides in soil is a rising concerns among the researchers in Malaysia because of higher pesticide usage in agriculture sector. Adsorption-desorption studies of pesticides such as metsulfuron-methyl, chlorpyrifos, fenvelerate, 2,4-D and paraquat (Cheah et al., 1997; Ismail and Maznah, 2006; Mehdi et al., 2009; Ismail and Ooi, 2012) have been reported. Although many studies on the adsorption/desorption of pesticides have been published, there is still lack of information on the adsorption-desorption behavior of thiram in soil, especially Malaysian soils. Adsorption-desorption studies help to understand the transport of the pesticides into the soil environment. Therefore, the prediction of impact of pesticides on non targeted organisms and groundwater resources can be avoided. The aim of the present study was to investigate the adsorption and desorption behavior of thiram in two types of soil, in order to evaluate the interaction of thiram on the adsorption-desorption processes at different levels of $\mathrm{pH}$ and temperature.

\section{MATERIALS AND METHODS}

\section{Soil characterization}

Soil from two different soil series were used in the present study namely: Inceptisols and Ultisols. The Inceptisols soil were collected from Sungkai, Perak $\left(03^{\circ} 18^{\prime} \mathrm{N}, 101^{\circ} 17^{\prime}\right.$ E) and the Ultisols soil were collected from Labu, Negeri Sembilan $\left(02^{\circ} 45^{\prime} \mathrm{N}, 101^{\circ} 49^{\prime} \mathrm{E}\right)$. Soil samples were collected from the surface layer $(0-10 \mathrm{~cm})$ after native grass (Eleusine indica [L.] Gaertn.) and its residues were removed. The soil was air-dried and passed through a 2-mm sieve to remove stones, debris, plant root and other larger particles. The soil was stored in the freezer at $4{ }^{\circ} \mathrm{C}$ to minimize the effects of microbial activity.

\section{Reagents and chemicals}

Analytical grade thiram $99.8 \%$ purity (tetramethylthiuram disulfide; Pestanal, Sigma-Aldrich, St. Louis, Missouri, USA) was obtained from Riedel-de Haen, Germany (Table 1). The stock solution of thiram $\left(1000 \mu \mathrm{g} \mathrm{mL}^{-1}\right)$ was prepared in acetonitrile and kept at $4{ }^{\circ} \mathrm{C}$ prior to analysis. All reagents used were of analytical grade, like acetonitrile and dichloromethane and chemical, calcium chloride $\left(\mathrm{CaCl}_{2}\right)$ were procured from Merck (Darmstadt, Germany). Purified
Table 1. Physico-chemical properties of thiram.

\begin{tabular}{lll}
\hline Chemical structure & IUPAC name & Tetramethylthiuram disulfide \\
\hline & Molecular formula & $\mathrm{C}_{6} \mathrm{H}_{12} \mathrm{~N}_{2} \mathrm{~S}_{4}$ \\
& Molecular weight & 240.44 \\
& Solubility in water & $0.0165 \mathrm{~g} \mathrm{~L}^{-1}\left(20^{\circ} \mathrm{C}\right)$ \\
& Vapor pressure & $2 \times 10^{-2} \mathrm{mPa}^{\circ}\left(25^{\circ} \mathrm{C}\right)$ \\
& $\mathrm{K}_{\text {ow }} \log \mathrm{P}$ & 2.1 \\
& Density, $\mathrm{g} \mathrm{mL}^{-1}$ & $1.36\left(20^{\circ} \mathrm{C}\right)$ \\
& $\mathrm{pKa}$ & 8.19 \\
\hline
\end{tabular}

Source: MacBean, 2012.

Kow: Octanol-water partition coefficient.

pKa: acid dissociation constant.

water was prepared using a Milli-Q water purification system (Millipore, Billerica, Massachusetts, USA) for highperformance liquid chromatography (HPLC) analysis.

\section{Adsorption equilibrium time studies}

Adsorption experiments were carried out in accordance to the standard batch equilibration method, using the batch equilibration technique (OECD, 2000). To minimize charges in ionic strength and to avoid dispersion, $0.01 \mathrm{M} \mathrm{CaCl}_{2}$ was used as the background solution (Wauchope et al., 2002). The stock solution of thiram was diluted with $0.01 \mathrm{M} \mathrm{CaCl}_{2}$ solution to obtain the working solution for the test. The experiment was conducted at the original $\mathrm{pH}$ value of each soil type. The tests were conducted in triplicate including blank samples.

Two grams of soil were weighed separately in $20 \mathrm{~mL}$ conical centrifuge bottles containing $10 \mathrm{~mL} 0.01 \mathrm{M} \mathrm{CaCl}_{2}$ solution and thiram concentration of $5.0 \mu \mathrm{g} \mathrm{mL}^{-1}$. The mixtures were shaken on a horizontal orbital shaker at $150 \mathrm{rpm}$ time intervals were at 20,40,60,120, 180, 240, $300,360,420,480,540$, and $600 \mathrm{~min}$. The temperature of the orbital shaker was set at $30 \pm 0.1{ }^{\circ} \mathrm{C}$ to stimulate the normal conditions in Malaysia. Next, the suspensions were centrifuged at $3000 \mathrm{rpm}$ for $20 \mathrm{~min}$ and the supernatant $(1.0 \mathrm{~mL}$ ) sieved through $0.45 \mu \mathrm{m}$ filter (Whatman, UK) in a syringe filter $(1.5 \mathrm{~mL})$ before injected into the HPLCphotodiode array detection (DAD) for quantification.

\section{Adsorption kinetic study}

Studies on adsorption kinetics were also conducted for both soil series. Two grams of soil were transferred into centrifuge bottle and $10 \mathrm{~mL} 0.01 \mathrm{M} \mathrm{CaCl}_{2}$ solution containing 1, 2, 3, $5,6,8$, and $10 \mu \mathrm{g} \mathrm{mL}^{-1}$ concentrations of thiram were added, respectively. These tests were conducted in triplicate, blank samples were used as control. Mixtures were shaken on a horizontal orbital shaker at $150 \mathrm{rpm}$ until equilibrium. Then, suspensions were centrifuged at $3000 \mathrm{rpm}$ for $20 \mathrm{~min}$, and the supernatant sieved through $0.45 \mu \mathrm{m}$ filter before being injected into the HPLC-DAD for thiram residue analysis.

\section{Adsorption on centrifuge bottle}

The method for determination of the thiram residue on the centrifuge bottle was conducted similar to that of the determination of equilibrium time except that there was no soil. 


\section{Desorption experiments}

Desorption experiments were performed immediately after the adsorption experiments. After the supernatant samples were decanted, $10 \mathrm{~mL}$ fresh $0.01 \mathrm{M} \mathrm{CaCl}_{2}$ solution (without thiram) was added into the same centrifuge bottles. The mixtures were shaken on a horizontal shaker at $150 \mathrm{rpm}$ for $24 \mathrm{~h}$. The suspensions were centrifuged at $3000 \mathrm{rpm}$ for 20 min and $1.0 \mathrm{~mL}$ aliquot was filtered before analysis. The process was repeated three times consecutively.

\section{Effect of temperature on adsorption}

The adsorption experiments were performed at three different temperature levels $\left(25,30\right.$ and $\left.35^{\circ} \mathrm{C}\right)$ in accordance to the weather in Malaysia. The concentration of thiram used was $5.0 \mu \mathrm{g} \mathrm{mL}^{-1}$. All samples were prepared in triplicate for each different temperature. The experiment was carried out in the same way as that of the kinetic study described above.

\section{Effect of $\mathrm{pH}$ on adsorption}

The effect of $\mathrm{pH}$ on adsorption of thiram were done at three different levels of $\mathrm{pH}(3,7$, and 10) by adjusting the $0.01 \mathrm{M} \mathrm{CaCl}_{2}$ solution with concentrated hydrochloric acid $(\mathrm{HCl})$ and sodium hydroxide $(\mathrm{NaOH})$, respectively. The concentration of thiram used was $10.0 \mu \mathrm{g} \mathrm{mL}^{-1}$. All samples were prepared in triplicate and for each respective $\mathrm{pH}$. The experiment was conducted in the same way as that of the kinetic study described above.

\section{Quantitative determination of thiram by HPLC-DAD}

The determination of thiram residue was carried out using the HPLC 1200 (Agilent Technologies, Santa Clara, California, USA), equipped with a diode array detector (DAD). The HPLC-DAD was fitted with an auto sampler and a $100 \mu \mathrm{L}$ loop. The column was $\mathrm{C}_{18}, 25 \mathrm{~cm} \times 4.6 \mathrm{~mm}$ id, $5 \mu \mathrm{m}$ (Supelco 581325-U, Ascentis, Sigma-Aldrich). The absorbance wavelength was $230 \mathrm{~nm}$. The flow rate phase was acetonitrile: water (Milli-Q pure water) in the ratio of $1: 1$ at the isocratic mode. The flow rate and injection volume were set at $1.0 \mathrm{~mL} \mathrm{~min}^{-1}$ and $20 \mu \mathrm{L}$, respectively.

\section{Data processing and statistical analysis}

All data were analyzed by the Excel 2000 (Microsoft, Redmond, Washington, USA) and SPSS software (IBM Corporation, Armonk, New York, USA). Adsorptiondesorption data were fitted to the Freundlich model. Soil sorption was characterized by the partition constant $\left(\mathrm{K}_{d}\right)$. The adsorption coefficient $\left(K_{d}\right)$ was defined by Equation [1]. The pesticide concentrations in the soil and soil solutions were fitted to the linearized Freundlich sorption isotherm (Equation [2]):

$$
\begin{gathered}
K_{d}=(x / m) / C_{e} \\
\ln x / m=\ln K_{d}+1 / n \ln C_{e}
\end{gathered}
$$

where, $x / m$ is the concentration of the pesticide adsorbed in the soil $\left(\mathrm{mg} \mathrm{kg}^{-1}\right), C_{e}$ is the concentration of the pesticide in the soil solution $\left(\mathrm{mg} \mathrm{L}^{-1}\right) ; 1 / n$ and $K_{d}$ are constants. The value $n$ is the energy distribution of the adsorption site (Liu et al., 2010). The adsorption coefficient $\left(K_{d}\right)$ was also calculated as a function of the organic $\mathrm{C}(\mathrm{OC})$ content and the organic matter (OM) of the soil in the Equation [3]:

$$
K_{O C}=K_{d} \times 10 / \% O C
$$

Other parameters for the adsorption process that can be calculated were the Gibb's free energy change $(\Delta \mathrm{G}$, cal $\mathrm{mol}^{-1}$ ) and the Hysteresis coefficient $(H)$ (Liu et al., 2010; Sharma et al., 2011). The Gibb's free energy change $(\Delta \mathrm{G})$ was calculated for the adsorption-desorption isotherms according to following equation:

$$
\Delta G=-R T \ln K_{O M}
$$

where, $R$ is the gas constant $\left(8.31 \mathrm{~J} \mathrm{~K}^{-1} \mathrm{~mol}^{-1}\right)$, and $T$ is the Kelvin temperature $(303 \mathrm{~K})$. The hysteresis coefficient $(H)$ was calculated for the adsorption-desorption isotherms according to the following equation:

$$
H=(n \text { desorption }) /(n \text { adsorption })
$$

where, $n$ desorption and $n$ adsorption are the Freundlich constants obtained for desorption and adsorption isotherms, respectively.

\section{RESULTS AND DISCUSSION}

\section{Soil physical and chemical properties}

The characteristics of the two soil are shown in Table 2. The texture of the Inceptisols and Ultisols were classified as clay loam and sandy clay loam, respectively. The soils were acidic with soil $\mathrm{pH}$ between 4.7 and 5.5. The OM content in the Ultisols was higher $(14.52 \%)$ compared to that of the Inceptisols $(3.91 \%)$.

\section{Adsorption equilibrium time}

Figure 1 shows the concentration of thiram adsorbed by the soil at different time intervals. Thiram adsorbed on to the soil decreased with increased shaking time. The adsorption equilibrium times of thiram in the Inceptisols and Ultisols were characterized by an initial rapid adsorption, which eventually reached a constant, and this could be due to the limited surface area on the soil particles for thiram adsorption. The adsorption kinetics exhibited two distinct stages, a very rapid adsorption at the initial stages (within $3 \mathrm{~h}$ ) followed by slow adsorption. After 5 and $6 \mathrm{~h}$ shaking in the Ultisols and Inceptisols, respectively, the adsorption of thiram became very slow and reached a constant after achieving equilibrium between the soil matrix and solution.

Table 2. The characteristics of the Inceptisols and Ultisols.

\begin{tabular}{lcc}
\hline Soil types (USDA) & Inceptisols & Ultisols \\
\hline Texture & Clay loam & Sandy clay loam \\
Sand, \% & 30.90 & 50.75 \\
Silt, \% & 31.73 & 28.32 \\
Clay, \% & 37.36 & 20.93 \\
Organic C, \% & 1.12 & 4.16 \\
Organic matter, \% & 3.91 & 14.52 \\
CEC, meq $100 \mathrm{~g}^{-1}$ & 7.32 & 13.35 \\
pH & 4.73 & 5.52 \\
\hline
\end{tabular}

CEC: Cation exchange capacity. 
Figure 1. The adsorption equilibrium time of thiram in Inceptisols and Ultisols.

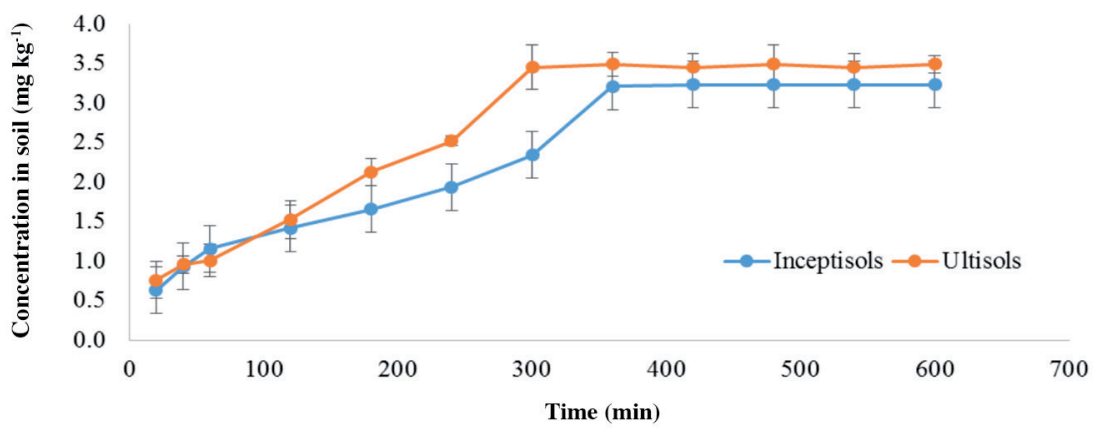

\section{Adsorption kinetics study}

The adsorption isotherms of thiram are presented in Figure 2. The adsorption isotherms of the fungicide thiram on the two soil were classified as L-type as the sorption kinetics corresponded to that of the L-type in the classification by Giles et al. (1960). The L-types isotherms represent a system where the solid surface has average affinity for the pesticide and the solvent is relatively inert, i.e., there is no strong competition from the solvent for adsorption sites (Fernandez-Perez et al., 2004; Sharma et al., 2011). This isotherm shape was also reported by ValverdeGarcia et al. (1988) to fit the adsorption of thiram onto eight Mediterranean soil types typical of Almería (Spain). Sharma et al. (2011) also did observe a similar isotherm for thiram adsorption onto three Indian soil types. A previous study by Filipe et al. (2009) showed that thiram adsorption onto humic acids was classified under L3 (class L, subgroup 3 ) and adsorption of thiram on activated $\mathrm{C}$ came under the L2 type (Zahoor, 2010). Control samples without soil, showed no losses of the fungicide thiram due to sorption on centrifuge tubes (graph not shown).

The Freundlich's adsorption-desorption coefficients $\left(\mathrm{K}_{d}\right)$ and other parameters were calculated from the plot of $\mathrm{Ln} X$ vs. $\mathrm{Ln} \mathrm{C}_{e}$ (not shown) and results are tabulated in Table 3. Correlation coefficients for the two soil series $\left(r^{2}>0.9\right)$ showed that all adsorption data fitted well to the Freundlich equation. The sorption of thiram was higher in the Ultisols $\left(\mathrm{K}_{d}=3.78\right.$ $\left.\mathrm{mL} \mathrm{g}^{-1}\right)$ than in the Inceptisols $\left(\mathrm{K}_{d}=2.10 \mathrm{~mL} \mathrm{~g}^{-1}\right)$. As expected, the adsorption of thiram in the Ultisols was higher than the Inceptisols. This could be due to the higher OM content in the Ultisols $(14.52>3.91)$. The data indicated that soil organic matter (SOM) adsorbed a greater amount of thiram per unit carbon therefore, a higher $\mathrm{K}_{\mathrm{oc}}$ value was found in soil with high OM. A similar observation was made by ValverdeGarcia et al. (1988) suggested that adsorption of thiram shows the better corresponds to the OM content in Almería soil. Filipe et al. (2009) also reported a strong interaction between thiram and commercial humic acids, suggesting the relevance of the OM content on thiram sorption onto soil. It is an established fact that higher OM (organic C) content in the soil increases the CEC value (Abat et al., 2012). A higher CEC value in the soil may provide more available sites for adsorption. The interaction between the pesticide and organic manure occurs via multiple bonding mechanisms,

Table 3. Adsorption/desorption parameters of thiram in Inceptisols and Ultisols.

\begin{tabular}{lcc}
\hline Parameters & Inceptisols & Ultisols \\
\hline Equation linear & $\mathrm{y}=0.734 \mathrm{x}-0.742$ & $\mathrm{y}=0.857 \mathrm{x}-1.331$ \\
$\mathrm{~K}_{\mathrm{d}}, \mathrm{mg} \mathrm{kg}^{-1}$ & 2.10 & 3.78 \\
$1 / \mathrm{n}$ & 0.734 & 0.857 \\
$\mathrm{r}^{2}$ & 0.964 & 0.960 \\
$\mathrm{~K}_{\mathrm{oc}}, \mathrm{mg} \mathrm{kg}^{-1}$ & 53.71 & 26.07 \\
Equation linear & $\mathrm{y}=0.856 \mathrm{x}-1.121$ & $\mathrm{y}=0.846 \mathrm{x}-1.741$ \\
$\mathrm{~K}_{\text {des }}, \mathrm{mg} \mathrm{kg}^{-1}$ & 3.07 & 5.70 \\
$1 / \mathrm{n}$ & 0.856 & 0.846 \\
$\mathrm{r}^{2}$ & 0.954 & 0.926 \\
$\Delta \mathrm{G}^{\circ}, \mathrm{kJ} \mathrm{mol}^{-1}$ & -1.87 & -3.35 \\
$H$ & 1.17 & 0.99 \\
\hline
\end{tabular}

Kd: Adsorption coefficient, Koc: organic carbon-water partition, Kdes: desorption coefficient, $\mathrm{r}^{2}$ : coefficient of determination, $\Delta \mathrm{G}^{\circ}$ : Gibb's free energy change, $H$ : hysteresis coefficient.

Figure 2. Adsorption isotherms of thiram in Inceptisols and Ultisols.

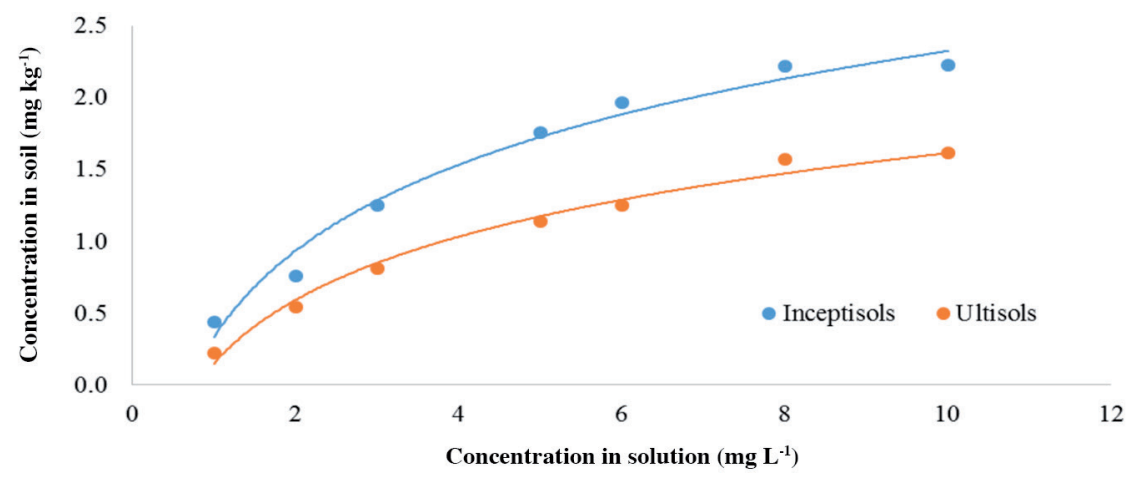


including ionic bonds between negatively charged $\mathrm{OM}$ and positively charged pesticides and/or hydrogen bonds in between the pesticides and OM (Durovic et al., 2009). The corresponding $1 / \mathrm{n}$ values observed for the Inceptisols and Ultisols were below unity, indicating that relative adsorption decreased with increasing solution concentration (Sharma et al., 2011).

The soil organic $\mathrm{C}$ partition coefficient $\left(\mathrm{K}_{\mathrm{oc}}\right)$ value for adsorption process were 53.71 and $26.07 \mathrm{mg} \mathrm{kg}^{-1}$ for Inceptisols and Ultisols soils, respectively. However, the $\mathrm{K}_{\mathrm{oc}}$ values measured in current study are lower as compared to the $\mathrm{K}_{\mathrm{oc}}$ values obtained by Filipe et al. (2010) for thiram adsorption onto luvisol soil were in the range $159-739 \mathrm{~mL} \mathrm{~g}^{-1}$. That can be due to the fact that $\mathrm{K}_{\mathrm{oc}}$ values depend on the adsorption-desorption coefficients $\left(\mathrm{K}_{d}\right)$ and the content of $\mathrm{OM}$ in the soil. Noted that the present study was conducted using different type of soil properties and experimental conditions. Hence, a big difference between measured and published values of $\mathrm{K}_{\mathrm{oc}}$ for thiram was observed.

The negative $\Delta \mathrm{G}^{\circ}$ (Gibbs free energy change) values obtained in the present study indicate that the adsorption of thiram onto soil is a spontaneous process and that the adsorption was an exothermic process. The $\Delta \mathrm{G}^{\circ}$ values of thiram adsorption were -1.87 and $-3.35 \mathrm{~kJ} \mathrm{~mol}^{-1}$ in Inceptisols and Ultisols, respectively. The negative $\Delta \mathrm{G}^{\circ}$ values indicate that the $\mathrm{H}$ bonds were the main interaction in the adsorption process in the soil (Li et al., 2011). This finding is in line with that of Zahoor (2010), who obtained negative $\Delta \mathrm{G}^{\circ}$ values for thiram adsorption onto activated $\mathrm{C}$ at various temperature levels.

\section{Desorption of sorbed thiram from soil}

The desorption process is an important process affecting the release of the pesticides from the soil, since it determines the potential mobility of the pesticides in the soil profile. Table 2 shows the Freundlich desorption coefficient $\left(\mathrm{K}_{\text {des }}\right)$ values of 5.70 and $3.07 \mathrm{~mL} \mathrm{~g}^{-1}$ as calculated for the Ultisols and Inceptisols, respectively. The desorption isotherms showed reasonably good fit with the Freundlich isotherms $\left(r^{2}>0.92\right)$.

Table 4 shows desorption results after three successive desorption processes in both soils. The results indicated weak binding of thiram to the soils, with $25.8 \%$ of the sorbed thiram being desorbed from the Inceptisols compared to $17.8 \%$ desorbed from the Ultisols at the first desorption processes. A similar desorption trend was observed for both the soil at the second and third desorption. The total detected

Table 4. Desorption of thiram in Inceptisols and Ultisols soil series.

\begin{tabular}{lccccc}
\hline & \multicolumn{2}{c}{ Inceptisols } & & \multicolumn{2}{c}{ Utisols } \\
\cline { 2 - 3 } \cline { 5 - 6 } Desorption & $\begin{array}{c}\text { Concentration } \\
\text { in solution }\end{array}$ & $\begin{array}{c}\text { Amount } \\
\text { desorbed }\end{array}$ & $\begin{array}{c}\text { Concentration } \\
\text { in solution }\end{array}$ & $\begin{array}{c}\text { Amount } \\
\text { desorbed }\end{array}$ \\
\hline & $\mu \mathrm{g} \mathrm{mL}^{-1}$ & $\%$ & & $\mu \mathrm{g} \mathrm{mL}^{-1}$ & $\%$ \\
1 & $1.29 \pm 0.05$ & 25.8 & & $0.89 \pm 0.04$ & 17.8 \\
2 & $0.75 \pm 0.02$ & 15.0 & & $0.66 \pm 0.06$ & 13.2 \\
3 & $0.54 \pm 0.01$ & 10.8 & & $0.41 \pm 0.02$ & 8.2 \\
4 & $0.00 \pm 0.00$ & 0.0 & & $0.00 \pm 0.00$ & 0.0 \\
Total & 2.58 & 51.6 & & 1.96 & 39.2 \\
\hline
\end{tabular}

of thiram desorbed from the Inceptisols and Ultisols was $2.58 \%$ and $1.96 \%$, respectively.

\section{Effect of temperature on adsorption}

The effect of temperature on the adsorption of thiram in both the soils is presented in Figure 3. The adsorption process at temperature 25,30 and $35{ }^{\circ} \mathrm{C}$ was found to be slightly consistent and percentage adsorbed was 25,30 , and $35^{\circ} \mathrm{C}$ were $67 \%, 64 \%$, and $73 \%$, in the Inceptisols soil and $77 \%$, $83 \%$, and $86 \%$ in the Ultisols, respectively. The results indicated that the adsorption of thiram in both studied soil were not affected by temperature.

\section{Effect of pH on adsorption}

The initial pH of the solution clearly affected the adsorption capacity of thiram. As shown in Figure 4, the adsorption of thiram on the Inceptisols and Ultisols soils were rather high at low $\mathrm{pH}$ values and decreased with increasing $\mathrm{pH}$ values of the solution. Thiram was easily adsorbed at pH 3 (almost $80 \%$ and $70 \%$ adsorbed) in the Ultisols and Inceptisols, respectively. However, at $\mathrm{pH} 10$, only $25 \%$ and $29 \%$ of the thiram was detected in the Ultisols and Inceptisols, respectively. This indicated that the availability of the adsorption sites for the thiram molecules reduced as the $\mathrm{pH}$ value increased. This finding is in accordance with the general trend observed for many various other pesticides (Liu et al., 2010; Cadkova et al., 2012; Olu-Owolabi et al., 2015). As expected, thiram is a weak acidic fungicide thus its speciation is $\mathrm{pH}$ dependent.

Figure 3. Effect of temperature on adsorption of thiram in Inceptisols and Ultisols.

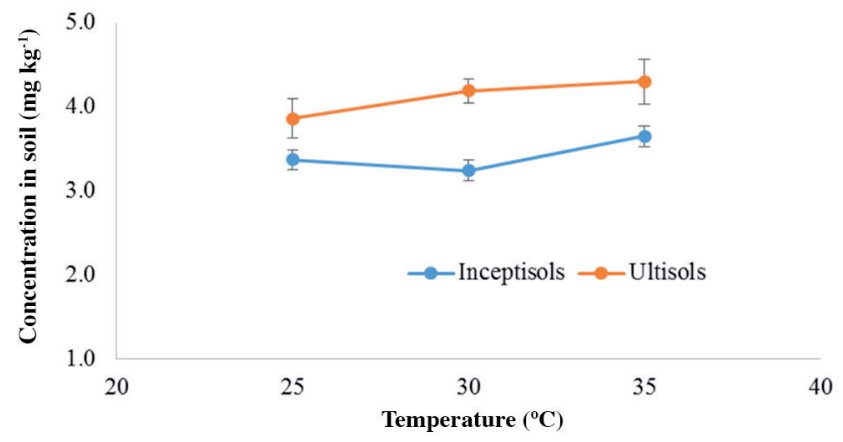

Figure 4. Effect of soil pH on adsorption of thiram in Inceptisols and Ultisols.

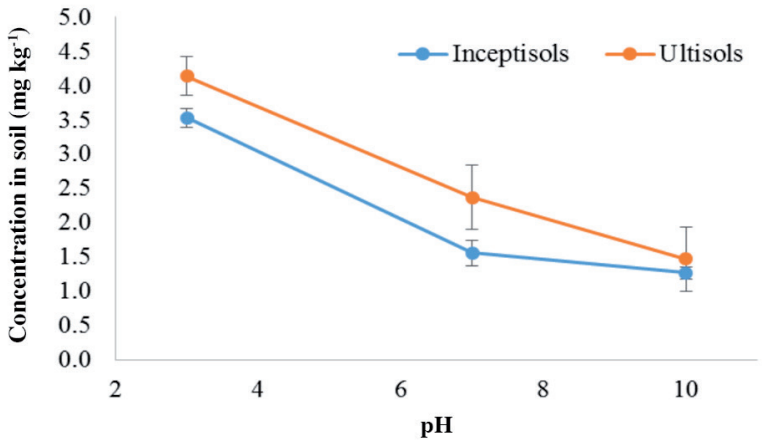




\section{CONCLUSION}

The results indicate that soil properties play a major role on the adsorption-desorption behavior of thiram, adsorption being greater in soils with higher soil organic and clay content. The adsorption of thiram was strongly affected by soil $\mathrm{pH}$, at $\mathrm{pH} 3$ adsorption was higher. However, the temperature of the soil does not contribute much to the adsorption of thiram. Results obtained in the present study demonstrate that organic matter/clay content and soil $\mathrm{pH}$ as a controlling factor for application of thiram in soil. Therefore, these findings will be enable the prediction of persistence and mobility of thiram in the soil with a similar soil properties.

\section{ACKNOWLEDGEMENTS}

The authors wish to acknowledge the Malaysian Palm Oil Board (MPOB) for sponsoring the present research under the Graduate Student Assistantship Scheme (GSAS). Special thanks are also extended to the Director General MPOB for permission to publish the paper. Sincere thanks are extended to the managers and the staff of Rubber Industry Smallholders Development Authority (RISDA), Sungkai and Labu Estate oil palm nursery for their kindness and cooperation.

\section{REFERENCES}

Abat, M., M.J. McLaughlin, J.K. Kirby, and S.P. Stacey. 2012. Adsorption and desorption of copper and zinc in tropical peat soils of Sarawak, Malaysia. Geoderma 175-176:58-63.

Berglof, T., W.C. Koskinen, M.J. Duffy, K.A. Norberg, and H. Kylin. 2003. Metsulfuron methyl sorption-desorption in field-moist soils. Journal of Agricultural and Food Chemistry 51:3598-3603.

Cadkova, E., M. Komarek, R. Kaliszova, V. Koudelkova, J. Dvorak, and A. Vanek. 2012. Sorption of tebuconazole onto selected soil minerals and humic acids. Journal of Environmental Science and Health, Part B: Pesticides, Food Contaminants, and Agricultural Wastes 47(4):336-342.

Cao, J., H. Guo, H.M. Zhu, L. Jiang, and H. Yang. 2008. Effects of SOM, surfactant and $\mathrm{pH}$ on the sorption-desorption and mobility of prometryne in soils. Chemosphere 70:2127-2134.

Cheah, U.B., R.C. Kirkwood, and K.Y. Lum. 1997. Adsorption, desorption and mobility of four commonly used pesticides in Malaysian agricultural soils. Pesticide Science 50(1):53-63.

Durovic, R., J. Gajic-Umiljendic, and T. Dordevic. 2009. Effects of organic matter and clay content in soil on pesticide adsorption processes. Pesticides and Phytomedicine 24:51-57.

Fernandez-Perez, M.F., F. Flores-Cespedes, E. Gonzalez-Pradas, M. Villafranca-Sanches, S. Perez-Garcia, and F.J. GarridoHerrera. 2004. Use of activated bentonites in controlled-release formulations of atrazine. Journal of Agricultural and Food Chemistry 52:3888-3893.

Filipe, O.M.S., S.A.O. Santos, M.R.M. Domingues, M.M. Vidal, A.J.D. Silvestre, C.P. Neto, et al. 2013. Photodegradation of the fungicide thiram in aqueous solutions. Kinetic studies and identification of the photodegradation products by HPLC-MS/ MS. Chemosphere 91:993-1001.
Filipe, O.M.S., M.M. Vidal, A.C. Duarte, and E.B.H. Santos. 2009. Adsorption-desorption behavior of thiram onto humic acid. Journal of Agricultural and Food Chemistry 57:4906-4912.

Filipe, O.M.S., M.M. Vidal, H.W. Scherer, R.J. Schneider, A.C. Duarte, V.I. Esteves, et al. 2010. Effect of long term organic amendments on adsorption-desorption of thiram onto a luvisol soil derived from loess. Chemosphere 80:293-300.

Giles, C.H., T.H. MacEwan, S.N. Nakhwa, and D. Smith. 1960. Studies in adsorption. Part XI. A system of classification of solution adsorption isotherms, and its use in diagnosis of adsorption mechanisms and in measurement of specific surface areas of solids. Journal of the Chemical Society 3973-3993.

Gupta, B., M. Rani, and R. Kumar. 2011. Degradation of thiram in water, soil and plants: a study by high-performance liquid chromatography. Biomedical Chromatography 26:69-75.

Halimah, M., H. Zulkifli, V. Subramaniam, Y.A. Tan, C.W. Puah, C.L. Chong, et al. 2010. Life cycle assessment of oil palm seedling production (Part 1). Journal of Oil Palm Research 22:878-886.

Ismail, B.S., and Z. Maznah. 2006. Adsorption-desorption and mobility of fenvalerate in three tropical agricultural soils. American-Eurasian Journal of Agriculture \& Environmental Science 1(2):160-168.

Ismail, B.S., and K.E. Ooi. 2012. Adsorption, desorption and mobility of metsulfuron-methyl in soils of the oil palm agroecosystem in Malaysia. Journal of Environmental Biology 33:573-577.

Kumar, N., I. Mukherjee, and E. Varghese. 2015. Adsorptiondesorption of tricyclazole: effect of soil types and organic matter. Journal of Environmental Monitoring 187:61-71.

Li, X., Q. Zhou, S. Wei, W. Ren, and X. Sun. 2011. Adsorption and desorption of carbendazim and cadmium in typical soils in northeastern China as affected by temperature. Geoderma 160:347-354.

Liu, Y., Z. Xu, X. Wu, W. Gui, and G. Zhu. 2010. Adsorption and desorption behavior of herbicide diuron on various Chinese cultivated soils. Journal of Hazardous Materials 178:462-468.

MacBean, C. 2012. The pesticide manual. $16^{\text {th }}$ ed. British Crop Production Council, Hampshire, UK.

Mathews, J., T.H. Tan, K.K. Yong, K.M. Chong, S.K. Ng, and W.M. Ip. 2010. Managing oil palm nursery: IOI's experience. The Planter 86(1016):771-785.

Maznah, Z., B.S. Ismail, and M. Halimah. 2012. Fate of thiram in an oil palm nursery during the wet season. Journal of Oil Palm Research 24:1397-1403.

Mehdi, S., M. Halimah, M. Nashriyah, and B.S. Ismail. 2009. Adsorption and desorption of paraquat in two Malaysian agricultural soils. American-Eurasian Journal of Sustainable Agriculture 3(3):555-560.

OECD. 2000. Guidelines for testing of chemicals, Section 1 (106): Adsorption-Desorption using batch equilibrium method in soils. Environmental Health and Safety Division, Organisation for Economic Co-operation and Development (OECD), Environment Directorate, Paris, France.

Olu-Owolabi, B.I., P.N. Diagboya, and K.O. Adebowale. 2015. Sorption and desorption of fluorene on five tropical soils from different climes. Geoderma 239-240:179-185.

Rama Krishna, K., and L. Philip. 2008. Adsorption and desorption characteristics of lindane, carbofuron and methyl parathion on various Indian soils. Journal of Hazardous Materials 160:559-567. 
Sharma, D.K., A. Gupta, and R. Kashyap. 2011. Polarographic determination of the fungicide thiram in relation to its environmental and toxicological analysis. Toxicological \& Environmental Chemistry 93:1319-1331.

Sherif, A.M., A.A. Elhussein, and A.G. Osman. 2011. Biodegradation of fungicide thiram (TMTD) in soil under laboratory conditions. American Journal of Biotechnology and Molecular Sciences 1(2):57-68.

Thomas, K.V. 2001. The environmental fate and behavior of antifouling paint booster biocides: a review. Biofouling $17: 73-86$
Valverde-Garcia, A., E. Gonzalez-Pradas, M. Villafranca-Sanchez, D. Del Rey-Bueno, and A. Garcia-Rodriguez. 1988. Adsorption of thiram and dimethoate on Almeria soils. Soil Science Society of America Journal 52:1571-1574.

Wauchope, R.D., S. Yeh, J.B.H.J. Linders, R. Kloskowski, K. Tanaka, B. Rubin, et al. 2002. Pesticide soil sorption parameters: theory, measurement, uses, limitations and reliability. Pesticide Management Science 58:419-445.

Zahoor, M. 2010. Removal of thiram from aqueous solutions. Journal of the Chinese Chemical Society 57:1361-1366. 